$1-2013$

\title{
Assessing the Effect of Food Exposure on Children's Identification and Acceptance of Fruit and Vegetables
}

Jennifer Schindler

Denise Corbett

Catherine A. Forestell

Follow this and additional works at: https://scholarworks.wm.edu/aspubs

Part of the Child Psychology Commons 


\section{Eating Behaviors}

\section{Highlights}

\section{Assessing the effect of food exposure on children's identification and} acceptance of fruit and vegetables

Jennifer M. Schindler ${ }^{a}$, Denise Corbett ${ }^{b}$, Catherine A. Forestell ${ }^{a}, *$

a The College of William \&' Mary, Williamsburg, VA, 23187, United States

b School Health Initiative Program, Williamsburg James City County Public Schools, Williamsburg, VA, 23188, United States

- Children (group FV-EXP) were exposed to healthy foods during a nutrition program. A control group (FV EXP) participated in the program but did not get food exposure. $>$ Both groups identified more fruit, but not vegetables, after the nutrition program. $>$ Group FV-EXP, tried more fruit, but not vegetables, after the nutrition program. $>$ Programs should expose children to healthful foods to increase their acceptance. 


\title{
Assessing the effect of food exposure on children's identification and acceptance of fruit and vegetables
}

\author{
Q13 Jennifer M. Schindler a , Denise Corbett ${ }^{\mathrm{b}}$, Catherine A. Forestell $\mathrm{a}, *$ \\ Q44 a The College of William \& Mary, Williamsburg, VA, 23187, United States \\ b School Health Initiative Program, Williamsburg James City County Public Schools, Williamsburg, VA, 23188, United States
}

\section{A R T I C L E I N F O}

\section{Article history:}

Received 21 May 2012

Received in revised form 11 September 2012

Accepted 24 October 2012

Available online $\mathrm{xxxx}$

\section{Keywords:}

Fruit and vegetable exposure

School nutrition program

Food acceptance

Obesity

\begin{abstract}
A B S T R A C T
Currently, fewer than $15 \%$ of children between the ages of 4-8 years consume the recommended levels of 21 fruits and vegetables. In order to address this serious public health issue, a variety of nutrition programs 22 have been implemented across the eountry, which have varied in their success. The present research ana- 23 lyzed the effectiveness of providing fruit and vegetable exposure as part of a school nutrition program. 24 Kindergarten students at two schools were $(\mathrm{N}=59)$ exposed to interactive activities about healthy eating 25 and physical activity. In addition, those at one school $(n=29)$ were exposed to a variety of fruits and vege- 26 tables as part of this program. Assessment of children's ability to identify and their willingness to try fruits 27 and vegetables before and after the program indicated that while all children were better able to identify a 28 range of fruit, only those who received exposure to healthful foods were more willing to try fruit after the 29 program. There were no changes in their identification or willingness to eat vegetables. These results suggest 30 that schools should provide exposure to a variety of healthy foods as part of their nutrition programs. Such 31 programs should focus specifically on exposing children to vegetables because increasing children's willing- 32 ness to try foods that are typically considered unpalatable may be especially challenging.
\end{abstract}

(c) 2012 Published by Elsevier Ltd. 34

\section{Introduction}

Nutrients from a diet that is rich in fruit and vegetables can contribute to the prevention of cancer and cardiovascular disease and may displace other less healthy foods, thereby reducing fat consumption (Hu et al. 2000; Liu et al., 2000). However, fewer than $15 \%$ of children between the ages of 4-8 years consume the recommended levels of fruits and vegetables (Guenther, Dodd, Reedy, \& Krebs-Smith, 2006). This is a serious public health concern given that eating habits established in childhood track into adulthood (Mikkila, Rasanen, Raitakari, Pietinen, \& Viikari, 2004).

Barriers exist that make it especially difficult for young children to improve their eating habits. From a biological perspective, children tend to prefer energy-dense foods, which are often sweet and salty, as opposed to healthier foods, such as vegetables-and fruit, which may be bitter or sour tasting (Desor, Mallor, \& Greene, 1977). In addition, children are often unwilling to try unfamiliar foods. This fear of new food experiences, referred to as neophobia has been identified as a factor in children's low consumption of fruits and vegetables (Cooke et al., 2004; Wardle, Carnell, \& Cooke, 2005).

\footnotetext{
* Corresponding author at: Psychology Department, The College of William \& Mary, P.O. Box 8795, Williamsburg, VA 23187-8795, United States. Tel.: +1 757221 3892; fax: + 17572213896 .

E-mail address: caforestell@wm.edu (C.A. Forestell).
}

In an effort to counteract these barriers to healthy eating in children, 58 government agencies and community groups have begun to develop 59 strategies that encourage healthy eating in children (CDC, 2007). 60 Because children spend a large amount of time in educational environ- 61 ments, schools are key venues for the nutrition intervention programs 62 (Mullen \& Shield, 2004). While 70\% of all states require nutrition and 63 dietary education (Kann, Telljohann, \& Wooley, 2007), the median 64 number of hours devoted to this topic is limited (i.e., $<5 \mathrm{~h}$ per year; 65 Story, Nanney, \& Schwartz, 2009). Moreover, while some programs 66 are effective at increasing attitudes towards healthy eating, many 67 programs do not successfully change children's eating behaviors 68 (Jan, Bellman, Barone, Jessen, \& Arnold, 2009; McCullough, Yoo, \& 69 Ainsworth, 2004; Seaman \& Kirk, 1995). Such findings suggest that 70 more work is needed to understand mechanisms underlying the devel- 71 opment of food preferences in order to create effective evidence-based 72 nutrition programs for children.

Recently, Reverdy, Chesnel, Schlich, Koster, and Lange (2008) 74 found that nutrition education that focused on the sensory experi- 75 ences of tasting unfamiliar foods decreased neophobia and enhanced 76 8-10 year old children's willingness to try healthful foods compared 77 to those not exposed to this program. This approach is consistent 78 with experimental findings that have shown that repeated exposures 79 to foods increases children's preferences for these foods (e.g., Birch, 80 McPhee, Shoba, Pirok, \& Steinberg, 1987; Gerrish \& Mennella, 2002; 81 Q5 Sullivan \& Birch, 1990). The research proposed herein aimed to ex- 82 pand upon these findings to determine whether food exposures 83 
presented as part of a nutrition education program increased children's ability to identify fruit and vegetables and their willingness to try them relative to those who did not receive such exposure.

The children examined in the current study participated in a School Health Initiative Program (hereafter referred to as SHIP), which uses multiple programmatic strategies to create and maintain healthy physical and social environments for children in all schools throughout the school district. For kindergarten students, this includes activities provided by the OrganWise Guys $®$ Program, 2010 (OWG, Duluth, GA), such as music, books, games, and activities that encourage healthy eating, and physical activity through daily stretches, and activity enhanced lessons. Over the course of the 2009-10 academic year children in one school additionally received exposure to a variety of fruit and vegetables provided by the USDA Fresh Fruit and Vegetable Program. This program is provided to select low-income elementary schools throughout the United States. Although $\$ 3$ million is allocated to this program annually, there has been relatively little evaluation of its impact on children's food preferences (Story et al., 2009). In the school that received this program, 57 different fruits and 23 vegetables were presented in the afternoon three times a week.

We hypothesized that kindergarten children who received fruit and vegetable exposures in addition to regular SHIP activities would be better at identifying and more willing to try a fruit and vegetables compared to those at another school who were exposed to SHIP only.

\section{Method and procedure}

\subsection{Participants}

The study consisted of a convenience sample drawn from two schools, both of which served children from Pre-Kindergarten to Grade 5 in the rural fringe of the county. One school employed the standard SHIP program, which consisted of OWG activities, and did not provide additional fruit and vegetable exposure (FV-UNEXP). Children at the other school received exposure to fruits and vegetables on a weekly basis (FV-EXP) in addition to the SHIP program.

At the beginning of the fall semester a letter and consent form were sent home to all parents of kindergarten students at both schools to solicit participation. All procedures were approved by the School Board and the William \& Mary Institutional Review Boards.

\subsection{Procedure}

Children's willingness to try fruits and vegetables was assessed by presenting four vegetables (acorn squash, baby spinach, cucumber slices, and sugar snap peas) and four fruits (pears, pink grapefruit, papaya, and kiwi) in 4 oz plastic containers in random order. All foods were presented raw, except for acorn squash (which was cooked) and prepared for consumption (e.g., chopped or sliced). For each food item, children were asked if they could identify the food, and if they would like to try it. Children could eat as much or as little of the food as they wished. Each container was sealed and put to the side after the child had an opportunity to try the food. Students' were tested once in the fall, at the beginning of the SHIP program, and again after 5 months of the program. Demographic information about the racial background, age, and lunch status (i.e., income level) of the children was obtained from school records.

\subsection{Data analyses}

The percentage of fruits and vegetables correctly identified and tried for each of the children during each of the tests was calculated and subjected to a mixed analyses of variance (ANOVA) with school (FV-UNEXP, FV-EXP) as the between subjects variable and test (baseline, post-test) as the repeated-measures variable. To determine whether income level interacted with test session, similar mixed analy- 143 ses which compared children's performance on these measures as a 144 function of their lunch status (free and reduced, regular price) and 145 test (baseline, post-test). A level of $P<.05$ was selected to indicate statis- 146 tical significance.

147

Additionally the percentage of children who correctly identified 148 and tried each fruit and vegetable was calculated for the baseline 149 and post-test. A series of Chi-square analyses were conducted sepa- 150 rately for each school to determine whether the number of children 151 who identified or tried any of the individual foods increased after 152 the program.

\subsection{Participant characteristics}

A total of 59 parents; 30 from FV-UNEXP and 29 from FV-EXP, provid- 156 ed consent for their children to participate and 58 students (i.e., 31 girls) 157 completed both test sessions. Participants were 5.4 years of age (range 158 5-6 years) at the beginning of the study. The racial background of these 159 children was as follows: Caucasian, 67.2\%; African American, 15.5\%; 160 Hispanic, 10.3\%; Asian, 5.2\%; and admixed-other, 1.7\%. Approximately 161 $61 \%$ of children at FV-EXP and 10\% children at FV-UNEXP received free 162 and reduced lunches $\left(\chi^{2}(1)=12.8, P<0.001\right)$, which are provided to 163 those whose parents' annual salary was less than $\$ 40,793$ for a family 164 of four (hereafter referred to as low income families).

\subsection{Test performance}

As shown in Fig. 1, children identified more of the fruits; $F(1,56)=167$ 25.7, $P<0.001, \eta^{2}=0.31$ at the end of the program regardless of the $168 \mathbf{Q} 7$ school they attended. As shown in Table 1, this increase was not due 169 to a change in the identification of any single fruit (all $P$ values $>0.3$ ). 17 In contrast to the fruits, identification of vegetables did not improve at 171 either school $(P>0.15)$.

With respect to the number of foods tried, there was a general 173 trend for more children to try each of the individual foods after the 174 program (Table 1), however these differences failed to reach signifi- 175 cance (all $P$ values $>0.1$ ). Analyses of the percentage of foods tried 176 by the children at each school revealed a significant school $\mathrm{x}$ test 177 interaction-for the number of fruits tried; $F(1,54)=4.8, P<0.05,178$ $\eta^{2}=0.082$. As shown in Fig. 1, while participants at FV-EXP tried sig- 179 nificantly more fruits after the SHIP program $(t(27)=2.4, P<0.03), 180$ those at FV-UNEXP did not. No differences were observed for their 181 willingness to try vegetables at either school.

Finally, to determine whether the children in the free and reduced 183 lunch group differed in their willingness to try the foods from the regu- 184 lar lunch group, we compared them on the number of foods they tried. 185 Because of the small number of students at FV-UNEXP in the reduced 186 lunch group $(n=3)$ we were unable to determine whether income 187

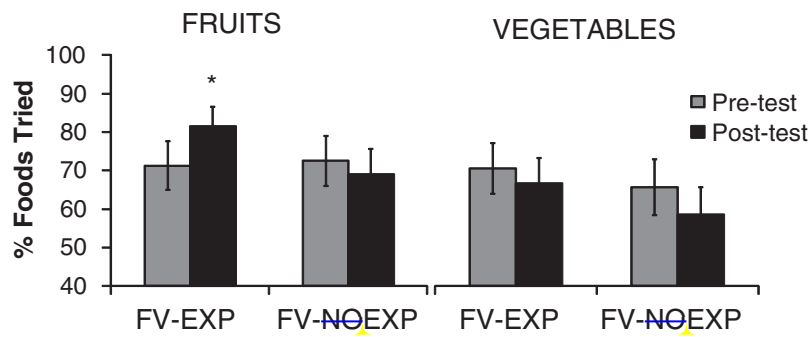

Fig. 1. Fruit and vegetable intake as a result of healthy food exposure. Students with FV-EXP who received exposure to fruits and vegetables as part of their nutrition program tried a greater percentage of fruits in the post-test compared to pre-test, whereas children with FV-NOEXP who did not receive food exposure as part of the SHIP program, tried a similar number of fruits in the pre- and post-tests. Children did not increase their vegetable intake at either school. *Indicates significant difference at $P<.05$. 
t1.1 Table 1

Q3t1.2 Percentage of children who identified and tried each food.

t1.3

$\mathrm{t} 1.4$

$\mathrm{t} 1.5$

$\mathrm{t} 1.6$

t1.7

$\mathrm{t} 1.8$

$\mathrm{t} 1.9$

t1.10

t1.11

t1.12

t1.13

$\mathrm{t} 1.14$

t1.15

$\mathrm{t} 1.16$

t1.17

t1.18

$\mathrm{t} 1.19$

t1.20

$\mathrm{t} 1.21$

$\mathrm{t} 1.22$

t 1.23

$\mathrm{t} 1.24$

t1.25

t1.26

$\mathrm{t} 1.27$

t1.28

t1.29

t1.30

\begin{tabular}{|c|c|c|c|c|}
\hline & \multicolumn{2}{|l|}{ FV-EXP } & \multicolumn{2}{|c|}{ FV-UNEXP } \\
\hline & Baseline & Post-test & Baseline & Post-test \\
\hline \multicolumn{5}{|l|}{ Fruit } \\
\hline \multicolumn{5}{|l|}{ Pears } \\
\hline \% Correct ID & 3.7 & 29.6 & 13.3 & 26.6 \\
\hline$\%$ Tried & 29.6 & 96.3 & 13.3 & 79.3 \\
\hline \multicolumn{5}{|l|}{ Grapefruit } \\
\hline \% Correct ID & 3.6 & 7.1 & 3.3 & 6.6 \\
\hline$\%$ Tried & 28.5 & 71.4 & 36.6 & 53.3 \\
\hline \multicolumn{5}{|l|}{ Papaya } \\
\hline \% Correct ID & 0 & 0 & 0 & 0 \\
\hline$\%$ Tried & 21.4 & 78.6 & 36.6 & 66.6 \\
\hline \multicolumn{5}{|l|}{ Kiwi } \\
\hline$\%$ Correct ID & 17.8 & 28.6 & 20.6 & 51.7 \\
\hline$\%$ Tried & 39.3 & 78.6 & 23.3 & 76.6 \\
\hline \multicolumn{5}{|l|}{ Vegetables } \\
\hline \multicolumn{5}{|l|}{ Acorn squash } \\
\hline$\%$ Correct ID & 3.6 & 3.6 & 0 & 0 \\
\hline$\%$ Tried & 28.5 & 35.7 & 56.6 & 40.0 \\
\hline \multicolumn{5}{|l|}{ Spinach } \\
\hline$\%$ Correct ID & 7.1 & 10.7 & 3.3 & 10.0 \\
\hline$\%$ Tried & 35.7 & 67.9 & 26.6 & 56.7 \\
\hline \multicolumn{5}{|l|}{ Sugar snap-peas } \\
\hline \% Correct ID & 3.6 & 0 & 3.3 & 3.33 \\
\hline$\%$ Tried & 42.9 & 71.4 & 30.0 & 63.3 \\
\hline \multicolumn{5}{|l|}{ Cucumbers } \\
\hline \% Correct ID & 57.1 & 67.9 & 43.3 & 50 \\
\hline$\%$ Tried & 17.9 & 85.7 & 33.3 & 70 \\
\hline
\end{tabular}

group interacted with the manipulation. However, a comparison of the income groups' responses revealed that those in the reduced lunch group tried more fruits $(t(56)=2.7, P<0.04)$ and vegetables $(t(56)=28.8, P<0.01)$ in both tests compared to those in the regular lunch group. Additionally, comparisons of children from each of the income groups at FV-EXP revealed that the change in the number of foods tried between the baseline and post-test was similar for both income groups at this school $(P>0.9)$.

\section{Discussion}

The present study demonstrated that whereas all children identified more foods, those who were exposed to fruits and vegetables in addition to SHIP tried more healthful foods compared to children without such exposure after 5 months of nutrition education. These findings support previous research demonstrating that while nutrition education may increase children's knowledge about healthful foods, it is not necessarily successful at changing children's willingness to try healthful foods (Reverdy et al., 2008). Rather, additional exposure to a variety of healthful foods may be an effective method for reducing neophobia (Birch et al., 1987; Gerrish \& Mennella, 2002; Pliner, 1982; Wardle, Herrara, Cooke, \& Gibson, 2003).

Although children with FV-EXP tried more fruit, they did not try more vegetables after the exposure period. Thus, as has been observed previously (Hendy, Williams, \& Camise, 2005, Mennella, Nicklaus, Jagolino, \& Yourshaw, 2008), children's liking for fruit did not generalize to vegetables, which differ substantially from fruits in their flavor profiles (i.e. taste, odor, and texture). Because vegetables are rich in phytonutrients that contribute to their bitter taste (Drewnowski \& Gomez-Carneros, 2000), and are lower in energy density, children tend to like fruits better than vegetables (Domel \& Thompson, 2002; Edwards \& Hartwell, 2002; Gibson, Wardle, \& Watts, 1998). It is worth noting that in the current study, less than half of the foods presented to the children as part of the USDA program were fruits. Given that shifts in preferences do not readily occur for unpalatable foods (Forestell \& LoLordo, 2004; Zeinstra, Koelen, Kok, \& de Graaf, 2008) children may have had insufficient opportunity to learn to like the flavor of the vegetables.
Children from low-income families were more willing to try the 224 healthful foods than the high-income children during the baseline 225 and post-tests. Although, there was no evidence that the USDA pro- 226 gram increased low-income children's willingness to try the foods 227 more than the high-income children, further research with larger 228 samples of children from a range of socioeconomic backgrounds is 229 warranted to further address this question.

This study supports previous findings demonstrating that although 231 children are generally aware of healthful food options, their eating 232 behaviors do not necessarily coincide with this knowledge (Pelchat \& 233 Pliner, 1995; Wardle \& Huon, 2000). The evidence that early and 234 repeated taste exposure can reduce neophobia and increase acceptance 235 of foods should inform children's nutrition programs. Because mere 236 exposure to the flavor of healthful foods is the key to increasing chil- 237 dren's liking and consumption of these nutrient-rich foods (Birch 238 et al., 1987), getting children to try foods is the first step in increasing 239 their consumption. Future research is warranted to determine whether 240 programs that provide fruit and vegetable exposure increase consump- 241 tion of these foods over the long-term, and whether the effects reported 242 here generalize to different forms or preparations of healthful foods. 243

These findings suggest that emphasis needs to be placed on exposing 244 children to a variety of vegetables in addition to fruit to increase their 245 acceptance of these healthful foods. Because the best predictor of chil- 246 dren's fruit and vegetable intake is whether they like the taste of these 247 foods (Resnicow et al., 1998) understanding the mechanisms that 248 underlie the development of food preferences is necessary to create ef- 249 fective evidence-based programs for improving children's eating habits. 250

\section{Uncited references}

Forestell and Mennella, 2007

Lee et al., 2006

Mokdadet at., 2004

Ogdenet al., 2010

Van Duyn and Pivonka, 2000

Funding for this study was provided by The College of William \& Mary (W\&M) to 258 the last author. W\&M had no role in the study design, collection, analysis or interpre- 259 tation of the data, writing the manuscript, or the decision to submit the paper for 260 publication.

\section{Contributors}

Forestell and Corbett designed the study and Forestell and Schindler wrote the 263 protocol. Schindler and Forestell conducted literature searches, tested the children, 264 and Schindler completed the statistical analysis. Forestell wrote the first draft of the 265 manuscript, which was based on a senior thesis prepared by Schindler and all authors 266 contributed to and have approved the final manuscript.

Denise Corbett, the second author of the manuscript, is the Coordinator of the 269 School Health Initiative Program at the Williamsburg James City County Schools, in 270 which all of the students in this study participated. However, she is not affiliated in 271 any way with the USDA Fresh Fruit and Vegetable Program, the effects of which 272 were evaluated in this study.

The authors would like to thank the following students: Alexandra Hayes, Evette 275 Becker, Lisa Kepple, Marissa Bonhomme, Arielle Paz, and Jennifer Mills for their technical 276 assistance, as well as Pamela Dannon; Janice Kailos, and the kindergarten teachers at the 277 participating schools for their cooperation and assistance. Jennifer Schindler is currently 278 a graduate student at the Mailman School of Public Health, Columbia University.

\section{References}

Birch, L. L., McPhee, L., Shoba, B. C., Pirok, E., \& Steinberg, L. (1987). What kind of expo- 281 sures reduces children's food neophobia? Looking vs. tasting. Appetite, 9(3), 171-178. 282 Centers for Disease Control and Prevention (2007). School Health Policies and Programs 283 Study 2006: Changes between 2000 and 2006. Atlanta: U.S. Department of Health 284 and Human Services (Available at http://www.cdc.gov/healthyyouth/shpps/2006/ 285 factsheet. Accessed September 8, 2012) 
Cooke, L. J., Wardle, J., Gibson, E. L., Sapochnik, M., Sheiham, A., \& Lawson, M. (2004). Demographic, familial and trait predictors of fruit and vegetable consumption by preschool children. Public Health Nutrition, 7, 295-302.

Desor, J. A., Mallor, O., \& Greene, L. S. (1977). Preference for sweet in humans: infants, children \& adults. In J. M. Weiffenbach (Ed.), Taste and development: The genesis of sweet preference (pp. 161-172). Washington, DC: US Government Printing Office.

Domel, S. B., \& Thompson, W. O. (2002). Fourth-grade children's consumption of fruit and vegetable items available as part of school lunches is closely related to preferences. Journal of Nutrition Education and Behavior, 34, 166-171.

Drewnowski, A., \& Gomez-Carneros, C. (2000). Bitter taste, phytonutrients, and the consumer: A review. American Journal of Clinical Nutrition, 72(6), 1424-1435.

Edwards, J. S., \& Hartwell, H. H. (2002). Fruit and vegetables-attitudes and knowledge of primary school children. Journal of Human Nutrition and Dietetics, 15, 365-374.

Forestell, C. A., \& LoLordo, V. M. (2004). The addition of saccharin to taste cues affects taste preference conditioning in thirsty rats. Learning and Motivation, 35, 391-405.

Forestell, C. A., \& Mennella, J. A. (2007). Early determination of fruit and vegetable acceptance. Pediatrics, 120, 1247-1254.

Guenther, P. M., Dodd, K. W., Reedy, J., \& Krebs-Smith, S. M. (2006). Most Americans eat much less than recommended amounts of fruits and vegetables. Journal of the American Dietetic Association, 106(9), 1371-1379.

Hendy, H. M., Williams, K. E., \& Camise, T. S. (2005). "Kids choice" school lunch program increases children's fruit and vegetable acceptance. Appetite, 45, 250-263.

Hu, F. B., Rimm, E. B., Stampfer, M. J., Ascherio, A., Spiegelman, D., \& Willett, W. C. (2000). Prospective study of major dietary patterns and risk of coronary heart disease in men. American Journal of Clinical Nutrition, 72, 912-921.

Jan, S., Bellman, C., Barone, J., Jessen, L., \& Arnold, M. (2009). Shape it up: A school-based education program to promote healthy eating and exercise developed by a health plan in collaboration with a college of pharmacy. Journal of Managed Care Pharmacy, 15(5), 403-413.

Kann, L., Telljohann, S. K., \& Wooley, S. F. (2007). Health education: Results from the School Health Policies and Programs Study 2006. Journal of School Health, 77(8), 408-434.

tee, J., Herman, W., McPheeters, M., \& Gurney, J. (2006). An epidemic profile of children with diabetes in the U.S. Diabetes Care, 29, 420-421.

Liu, S., Manson, J. E., Lee, T. M., Cole, S. R., Hennekens, C. H., Willett, W. C., et al. (2000). Fruit and vegetable intake and risk of cardiovascular disease: The women's health study. American Journal of Clinical Nutrition, 72, 922-928.

McCullough, F. S. W., Yoo, S., \& Ainsworth, P. (2004). Food choice, nutrition education and parental influence on British and Korean primary school children. International Journal of Consumer Studies, 28(3), 235-244.

Mennella, J. A., Nicklaus, S., Jagolino, A. L., \& Yourshaw, L. M. (2008). Variety is the spice of life: Strategies for promoting fruit and vegetable acceptance in infants. Physiology $\mathcal{E}$ Behavior, 94, 29-38.

Mikkila, V., Rasanen, L., Raitakari, O. T., Pietinen, P., \& Viikari, J. (2004). Longitudinal changes in diet from childhood into adulthood with respect to risk of cardiovascular diseases: The cardiovascular risk in young Finns study. European Journal of Clinical 332 Nutrition, 58(7), 1038-1045. 333

Mokdad, A., Marks, J., Stroup, F., \& Gerberding, J. (2004). Actual causes of death in the 334 United States, 2000. Joumal of the American Medical Association, 291, 1238 1245. 335

Mullen, M., \& Shield, J. (2004). Childhood and adolescent overweight: the health profes- 336 sionals guide to identification, treatment and prevention. Chicago: American Dietetic 337 Association.

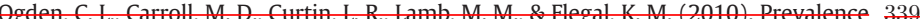
of high body mass index in US children and adolescents, 2007 2008. Journal of the 340 American Medical Association, 303, 242249.

OrganWise Guys (2010). http://www.organwiseguys.com/index.php (Accessed June 342 15, 2010) 343

Pelchat, M., \& Pliner, P. (1995). “Try it: you'll like it”; effects of information on willing- 344 ness to try novel foods. Appetite, 24, 153-531. 345

Pliner, P. (1982). The effects of mere exposure on liking for edible substances. Appetite, 346 3, 283-290.

Resnicow, K., Smith, M., Baranowski, T., Baranowski, J., Vaughan, R., \& Davis, M. (1998). 348 Two-year tracking of children's fruit and vegetable intake. Journal of the American 349 Dietetics Association, 98, 785-789.

Reverdy, C., Chesnel, F., Schlich, P., Koster, E. P., \& Lange, C. (2008). Effect of sensory 351 education on willingness to taste novel food in children. Appetite, 51, 156-165. 352

Seaman, C., \& Kirk, T. (1995). A new approach to nutrition education in schools. Health 353 Education, 3, 31-33.

Story, M., Nanney, M. S., \& Schwartz, M. B. (2009). Schools and obesity prevention: 355 Creating school environments and policies to promote healthy eating and physical 356 activity. The Milbank Quarterly, 87, 71-100.

Sullivan, S. A., \& Birch, L. L. (1990). Pass the sugar, pass, the salt: Experience dictates 358 preference. Developmental Psychology, 26, 546-551. 359

Van Duyn, M. A. S., \& Pivonka, E. (2000). Overview of the health benefits of fruit and 360 vegetable consumption for the dietetics professional: Selected literature. Journal 361 of the American Dietetic Association, 100, 1511-1521.

Wardle, J., Carnell, S., \& Cooke, L. (2005). Parental control over feeding and children's 363 fruit and vegetable intake: How are they related? Journal of the American Dietetic 364 Association, 105(2), 227-232.

Wardle, J., Herrara, M. L., Cooke, L., \& Gibson, E. L. (2003). Modifying children's food 366 preferences: the effects of exposure and reward on acceptance of an unfamiliar 367 vegetable. European Journal of Clinical Nutrition, 57, 341-349. 368

Wardle, J., \& Huon, G. (2000). An experimental investigation of the influence of health 369 information on children's taste preferences. Health Education Research, 15(1), 370 39-44.

371

Zeinstra, G. G., Koelen, M. A., Kok, F. J., \& de Graaf, C. (2008). Children's hard-wired aver- 372 sion to pure vegetable tastes. A 'failed' flavour-nutrient learning study. Appetite, 52, 373 528-530. 